\title{
Virtual collaboration, 'perezhivanie' and teacher learning: A socio-cultural-historical perspective
}

Victoria Antoniadou

Universitat Autònoma de Barcelona, Barcelona, Spain

(Article received 22 July 2011; final version received 30 September 2011)

This article discusses specific examples of virtually mediated interactions involving two transatlantic groups of student-teachers who engaged in a task-based telecollaborative project for the purposes of a teacher education course. The Vygotskian framework of learning and development and particularly the construct of Zone of Proximal Development (ZPD) in a collaborative frame serve as the theoretical basis of this study. This article aims to: (1) analyze the essentially language-mediated interactions to trace instantiations of virtual collaboration developmentally (2) discuss teacher learning outcomes of the (tele)collaborative activity, and (3) examine learning as expansion of what was explicitly proposed as objectives of the course, resulting from reasoned action i.e., reflection on the process and outcomes of the activity. The findings suggest that the effective integration of telecollaborative activities in pre-service teacher education programmes can enhance teacher learning in significant ways.

\section{Introduction}

New world, new tools, new practices: In the era of globalization and digitalization, education is confronted with the challenge - and often accused of not being able to adequately respond- to transform existing teaching and learning practices in order to embrace the new international character of the world; a world where borders between nations have been abolished, and the globe is viewed as one big nation due to the increasing dependence on computer technologies and social networking tools. There is a substantial discussion about what is nowadays called Teacher 2.0 (Dooly, 2010), a term used to define and describe the new roles, requirements, and competencies that teachers in this new era need to fulfil.

In this 'new world' the European guidelines for student-teachers of languages, (European Portfolio for Student-Teachers of Languages: EPOSTL) highlight the competence to integrate network-based activities to organize project-based learning for the 
promotion of language learning and intercultural communicative competence, and puts forward its implications for independent, lifelong learning. According to the EPOSTL, future teachers should be able to effectively integrate technology in their teaching practices, create online learning environments and activities to engage students in interaction with a worldwide community in order to facilitate authentic foreign language learning through group work and joint construction of knowledge.

Literature related to (teacher) education and technology identifies a gap between teacher training programmes offering 'isolated work in CALL' - which often does not include network-based environments, and situated technology experiences (Dooly, 2009; Egbert, Paulus, \& Yoko Nakmichi, 2002). While SLA research highlights the affordances of integrating of Information and Communications Technology (ICT) and network-based activities for language learning, the actual implementations of network based activities in teaching practice are scarce; this disproportion is often attributed to organizational challenges inherent to the reality of network-based implementations (Dooly, 2009).

In line with the above, this article explores learning outcomes resulting from the integration of Internet-mediated collaboration in a pre-service teacher education programme at the Universitat Autònoma de Barcelona, Spain (UAB), drawing on the particular case of one student teacher who worked together online with her University of Illinois Urbana-Champaign, USA (UIUC) peers towards the tasks she (and her other classmates) were assigned (teaching unit and podcast). First, the article analyzes the essentially language-mediated interactions to trace instantiations of virtual collaboration; second it discusses final teacher learning outcomes of the (tele)collaborative activity; and third, the article examines learning developmentally as expansion resulting from reasoned action i.e., critical reflection on the process and outcomes of the activity.

Given that the application of telecollaboration in teaching practice was not stated as an explicit goal of the activity, we consider outcomes that go beyond what was explicitly stated as course objectives as a 'creative leap' that leads to expansion of learning. In this case, a 'creative leap' consisted first in a critical reflection on telecollaboration as a valuable practice for teaching language, second, perception of specific affordances of this practice for authentic collaborative language learning (from the perspective of teacher) and 
third, implementation of this newly-acquired knowledge in practice and acknowledgement of own teacher knowledge base.

\section{Sociocultural-historical perspectives on learning and cognition}

Cognition is not the accumulation of theoretical out of context information; it is never an individual achievement, and it does not happen in isolation. According to socioconstructivist premises, knowledge is inherently social in nature. It is deeply rooted in the social and material conditions that make up the context of every human activity; in other words, the social context is not only what influences the development of higher mental functions but it is the source of every human developmentally-oriented activity (Vygotsky, 1978; Wertsch 1991; Rogoff, 2003; Johnson, 2006; Veresov, 2008).

This approach to knowledge creation and acquisition is clearly reflected in Vygotsky's eminent work on child-parent interactions and the importance of these interactions in the child developing higher mental functions. According to his theory of Zone of Proximal Development (1978) the meaning of the dyadic interaction of parentchild as source of child cognitive development lies on the presence of a 'More Knowledgeable Other' who provides the resources (in the form of signs or tools) for the less-knowledgeable one to reach a higher level of cognitive development than could be achieved on an individual level.

Conveying the implications of Vygotsky's investigation from dyadic interactions to multi-subject interaction, current sociocultural-historical theory postulates that community plays a central role in the process of making meaning as the basis for learning leading development. Knowledge is socially created, within a community, where individuals depend on and are accountable to each other to construct understandings, meanings, or find solutions to a common problem or to create an artefact i.e., product of their learning.

However, not every social interaction leads to learning and not every aspect of social interaction becomes a psychological tool for self-regulated thought. Veresov (2008) confers a word of caution against unproductive and misleading generalizations of this conceptualization and highlights Vygotsky's observation that only those aspects of the inter-mental plane for which there is dramatic collision, i.e., a situation that creates inner 
tension or that engages the subjects' interest, motives, and emotions. Vygotsky called this investment in an activity by the subject as 'perezhivanie', which he described as "the integration of cognitive and affective elements, which always presupposes the presence of emotions" (Daniels, 2008: 43). On the same account, Vygotsky (1986) proposes understanding the "affective-volitional tendency" (p.252) that underlies any human activity in order to answer all the whys in regards to a learning situation. In short, this means that engaging in meaningful activities that require emotional investment by the participants become relevant to comprehending the emergence of cognition.

\section{How do all these relate to educational practices?}

The "sociocultural turn" (Lantolf \& Thorne, 2005; Johnson, 2006) to the understanding of human learning has inspired researchers and educators to several applications. In teacher education, researchers have identified important implications of the sociocultural line of thought. As Johnson (2009) points out, some of the most important implications of Vygotsky's theory for teacher education and the purpose of teacher education are to be found in his distinction between everyday and scientific concepts, the feeling of emotional tension that is entailed in the movement from everyday and scientific concepts and its potential in creating a space for learning (Golombek \& Johnson, 2004), thus accounting for 'perezhivanie' learning scenarios. In the case of teachers (pre-service or in-service) everyday concepts are the ideas, opinions, and experiences about what a teacher is and how to teach, which derive, to a large extent, from their own background as learners and previous academic background. The role of teacher education programmes, therefore, is to mediate the process in which the teachers move beyond everyday concepts toward more theoretically and pedagogically sound instructional practices (Johnson, 2009: 2) by providing the mediational means for teachers to associate concrete examples of practical experience with theoretical concepts in order to understand their practices. 


\section{The study}

\section{Participants}

There were seven participants studying at the Universitat Autònoma de Barcelona (UAB), Spain and fourteen student-teachers studying at the University of Illinois at UrbanaChampaign (UIUC), USA. The UAB student-teachers were undergraduate students in their final year of Initial Teacher Education and specialized in English as a Foreign Language, while the UIUC groups were MA students specializing in CMC for teaching English as a Second Language.

The UAB group of student-teachers were novices to the teaching profession, with very little to no experience as language teachers. On the UIUC side, the student-teachers had varied experience in teaching English as a Second Language. Throughout the year the author/researcher assumed the role of the participant observer in the activities undertaken by the UAB group so this article focuses on the UAB side of the exchange.

\section{Course description}

The year-long teacher training course consisted of three tiers or layers, online and offline, running in parallel. One tier was at the school where the student-teachers observed experienced English practitioners teach English to primary school students; the second tier was at the university where they attended weekly tutorials, discussed school experiences and engaged in various tasks related to their degree, and the third tier was carried out online where the students engaged in virtual interaction with the UIUC group. Moreover, the student teachers were given a summary of the skills required by student-teachers as set in the European Portfolio for Student-Teachers of Languages (EPOSTL) as a reflective tool for them to monitor their progress throughout the course.

The telecollaborative exchange lasted one year, distributed across two semesters and involved two final outcomes: (1) a teaching unit and (2) a podcast and follow up activities. Due to space limitations, this article only considers the process behind the task of designing a teaching sequence (first semester) and presents examples of interaction related to this task. 
By integrating a telecollaborative format to the standard curriculum, the teachers planned to set up a 'virtual' collaborative construction of knowledge environment involving student-teachers working together toward a common task. The idea was to give the studentteachers the opportunity to receive an additional source of feedback in the process of designing their teaching units, more than the feedback they got in the classroom by their university peers, the tutor, and the school teacher, and this way enhance the feeling of belonging in a social community of peers- which in this case could only be achieved through virtual communication. It was also the opportunity to experience/learn educational technology and telecollaboration by doing educational technology and telecollaboration by means of freely available Web 2.0 tools. Although not clearly stated as an objective of the course, this activity was meant as an implicit incentive for student-teachers to use telecollaboration in their future teaching practices. The final aim of these activities was to foster self-reflection on their own practice and promote critical thinking -remaining consistent with the curriculum for teacher education which is based on a reflective model of teacher training (Antoniadou, 2011).

\section{Methodology}

\section{Data collection}

The data used in this article -which derive from a larger corpus of data- were ethnographically collected (and following the subjects' written consent) during the academic year 2009-2010 at the Universitat Autònoma de Barcelona, and are included in a larger doctoral thesis ${ }^{1}$ on teacher development, which is currently in progress. The database includes eighteen hours of audio and video recordings of the university tutorials (first semester $)^{2}$; online chats, student teachers' journals describing the experiences (observations, practices) that they considered important during their school placement, reports (during the course and final reflections in wiki format), and individual rankings of the formal competences articulated in the EPOSTL.

This study uses the concept of network-based collaborative activity to (1) understand and interpret reality that unfolded in this particular virtual setting of teacher 
training mediated by social and tool interaction; (2) conduct a bottom-up analysis to uncover the 'reality' of this concrete semiotically-mediated activity as a historically unfolding process relying on the situated experiences of the participants (emic approach), which they make available in their online interactions and final reflections.

\section{Analytical Approach}

The preliminary analysis (in order to select data for more in-depth analysis) departs from an emic perspective to reading the data; it consists in a grounded content analysis (Glaser \& Strauss, 1967) of recurrent themes and the formulation of a coding system of representation. Also, the findings reflect the attempt for an in-depth understanding of what happened through triangulation of different types of data that were gathered at different times of the course.

Next, the researcher used the Action-Relevant Episodes methodology (ARE), proposed by Barab, Hay, and Yagamata-Lynch (2001) to signal out 'episodes of action' and emerging learning-to-be-a-teacher instances from the chats. Barab, et al. define each ARE as the "minimal meaningful ontology for capturing cognition in situ" (p.64); thus AREs are the "minimal building blocks in constructing a particular trajectory" (2001: 70). To this account, they propose five entities that could minimally describe and make sense of this construction; namely issue at hand, initiator, participants, resources, and practice. Thus, cognition and development can be traced historically and signify transformation; for example, from issue at hand to a tool-related practice or from a resource-related practice to a tool-mediated practice.

Also, modified conversation analysis (CA) is used, when applicable (e.g. in chat transcripts). It is acknowledged that $\mathrm{CA}$ cannot be applied in its strictest sense to interactions that are not completely oral. However, it is argued here that text chat imitates enough of the conventions of face-to-face oral interaction to be analysable in many similar ways (Dooly, 2011). Other output, such as wikis, are also considered to be forms of intentional communication, allowing for extraction of speaker/writer intentions and are analysed accordingly. 


\section{The analysis}

Relaying the virtual collaborative experience over time: The genesis of "perezhivanie"

In the first two university tutorials the student-teachers were asked about their ideas and opinions regarding teacher roles and teaching methodologies based on their experiences up to that moment. It became apparent that the student-teachers' understanding and perception of what a language teacher is, how and what they should teach drew heavily on their backgrounds as language learners, which did not include technology-based instruction, as well as their academic formation as teachers during the previous two years of their teaching studies at the university (this background was largely theoretical i.e., it did not yet involve intensive participation and practical teaching at the school). When the tutor introduced the telecollaborative exchange and the web technologies to be used, the participants showed concern regarding the use of technologies that were 'unknown' to them for formal academic purposes.

Alicia $^{3}$, who is the focus in this article, first asked "But can we use Voicethread in primary?" wondering about the actual application of these technologies in the primary classroom. This episode of expressing concerns about the integration of 'unknown' technologies with transatlantic peers continued when the tutor proposed Zoho writer as a mediating tool for the exchange.

Extract 1: First University Tutorial, October 6, 2009; Jaume, Alicia, University Teacher

JAU Zoho oh Zoho yes

ALI but we haven't used Zoho before for these things

UT you WILL be using Zoho (laughing)

JAU yeah (laughing)

ALI (laughing)

UT you will be using Zoho for the exchange with your peers [...] I've used them both. All these are ... you can use word you know word okay googledocs and Zoho are word processors ONLINE so that means that instead of you doing a document or something and then sending it to Adrian and Adrian sending it back to you you DO it in the word processor online you say okay I'm going to invite some s- uh Alicia to EDIT what I've done and all you have to do is go into on that space ONLINE to edit okay/ it's a way of sharing a document and not having to send it ten thousand times that's all it is okay I promise I mean it's not complicated um

ALI okay

Bellaterra Journal of Teaching \& Learning Language \& Literature. 4.3

(Sept-Oct 2011): 53-70. ISSN 2013-6196. 
Despite the teacher educator's affirmative response to the possibility of using educational technologies in primary education and reassurance about technology-mediated learning, Alicia seems to remain sceptical about the idea of telecollaboration, the use of unfamiliar technologies and how she, as a teacher, could benefit from it.

Extract 2: (Second university tutorial, October 13, 2009), Researcher, Alicia

RES Do you have anything else to add to this? What do you think you can gain from this experience $[\ldots]$

ALI I think i learn more as a teacher in the school

RES m-hm

ALI in the class looking at the teachers there than here talking about it also

helps me but $i$ think I'm learning more I'm learning more everyday I ' $m$ there if I'm in the class and dealing with everything looking at how the other teachers...

At this point, she does not identify any direct link between doing telecollaboration and learning to be or being a teacher in primary education, nor does she see the relevance of working in virtual communities to knowledge construction, learning, or meaning making.

(Tele)collaboration as activity mediating development: undertaking "perezhivanie”

The following examples (shown sequentially) illustrate a collaborative scenario, mediated by the virtual setting, which echoes directly the Vygotskian thinking of ZPD; in this case the socially-mediated interaction has a concrete cognitive impact on the subject. At the beginning of the course, Alicia produces a first draft of her unit, where she formulates learning objectives for her students as is seen in figure 1.

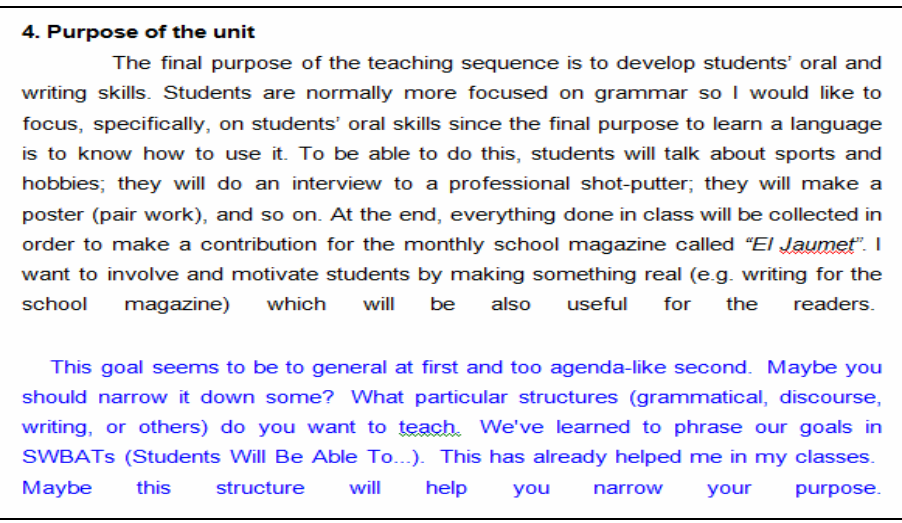

Figure 1: Draft of Teaching Sequence in Wiki 
In this episode it appears that Alicia still has a rather vague idea of what the construct or structure of SWABT (Students will be able to...) represents for teachers and how it is applied in practice. This structure, both as an acronym and its full expression as teacher terminology, had been elaborated in her Teaching Methods course but her use of the structure in her first teaching unit draft (develop oral and writing skills) indicates that she is unable to name specific topics, only to give general aims. At this point, Alicia is not able to adequately apply this structure of 'SWBATs' to effectively set up objectives for her students. Based on what follows, we could, in Vygotskian terminology, say that its adequate use remains in her ZPD.

In this first draft, the UIUC peer, Eve, comments that the objectives Alicia described in her draft seem too general and resemble an agenda of what Alicia plans to do (Eve's comments are marked in blue). Eve -positioned here as the 'more knowledgeable other'- brings up the SWABT (Students Will Be Able To) structure, which is familiar and useful to teachers, and suggests that Alicia could use it to formulate more specific goalsperhaps even assuming at that time that Alicia was not familiar with this structure. Shortly after this comment, Alicia met again with her peers online and the discussion on this issue continued.

1 Eve dice: Alicia, I really like your SWBAT as a list of activities, but the idea behind SWBAT is more to talk about what students will be able to do linguistically and this is how you can assess them [...]

2 cho73@illinois.edu dice: you can make assessing standard for exmaple, content, how clear...

3 Alici@! dice: that's another interesting point I've borrowed from you (SWABTS)

4 Eve dice: you're welcome

5 Alici@! dice: so poster format?

6 Eve dice: But SWBAT is more like, "students will be able to use key english phrases in presenting a poster about their favorite sport." the language use is the key part of SWBAT

7 Alici@! dice: Thanks for the clarification! is good to have USA peers

Figure 2: Online chat transcript 1

The UIUC peer, Eve, brings forth the issue of SWABT again, this time stating clearly that she recognizes Alicia's use of SWABT as a way of setting a list of activities towards a final outcome and moves on to a clarification of the SWABT structure, specifying that this is a heuristic device that teachers use to set linguistic objectives for students with direct relevance and implications for assessment (turn 1). Cho builds on Eve's mention of 
assessment by suggesting assessment standards (turn 2). The same issue at hand (SWABT) continues in turn 3; Alicia recognizes her peers' contribution in drawing her attention to the SWABT structure but Eve does not drop the matter but reinforces her explanation of SWABT through specific examples. She links her explanation with Alicia's final product (having the students create a poster about their favourite sports) to show how the SWABT structure would refer to the specific language the students were expected to use for producing the poster (turn 6).

In her final unit design, we may infer that Alicia has internalized or, as Vygotsky (1981) would say has appropriated this explanatory feedback of her peer. She transforms the external social feedback to an internalized psychological tool to express her thinking of teaching objectives. In other words, she creates a "bridge between external and internal activity" (Zinchenko, 1985: 106). The explanation she received from her peers about SWABT eventually leads to internalization or appropriation of the external semiotic means (i.e., explanation, definition of SWABT), which is registered as a clear formulation of linguistic objectives in her final teaching unit design.

4. Purpose of the unit
iThe SWBAT methodology for planning and phrasing the objectives of my teaching sequence
unit will be the following one:
Objectives (Students will be able to)
- Recognize (oral and written) and produce some of the basic vocabulary*
- Sing a song while dancing
- Ask each other "Do you like (swimming)?"
- Read English interview
- Brainstorm questions for an interview (catalan allowed)
- Translate these questions into English
- Do an interview
- Do a poster about any sport (main information)
- Do a poster's presentation

Figure 3: Final Draft (wiki): resource-mediated practice

In her final report, Alicia herself referred to the online chat as a "powerful resource" directly related to her acquiring linguistic repertoire related to teaching as well as enabling her to actually apply it in practice. She does no longer need "other-regulation" or any kind external of means to use the SWABT structure for setting linguistic objectives in her units. 
Developmentally speaking, we would say that the final product (final draft) signifies the process of transition from social (between individual and more knowledgeable other) to individual functioning registering a qualitatively different reorganization of the system of activity i.e., setting objectives for students using the SWABT structure.

\section{Tracing virtually-mediated teacher development over time: Implications for ICT-mediated professional teaching}

Development in this article is investigated as the dynamics of evolving participation in a virtual community. Alicia's trajectory toward development in this instance moves from familiarizing to coping with to practicing material conditions of telecollaboration. Using Barab et al. (2001) terminology to conceptualize and historically trace this development over time, we may see this development in the movement between what initially was issue an at hand (i.e., doing telecollaboration via 'unknown' web technologies) to tool- mediated practices (i.e., experiencing the social-material conditions of telecollaboration; doing collaborative activity; and actively participating by giving, receiving, and critically assessing feedback and ideas).

The telecollaborative activity had both cognitive and affective facets. Alicia and her peers invested cognitively and psychologically to the development of this activity, and this mutual investment contributed to the formation of what Vygotsky called 'perezhivanie' causing dramatic collision with Alicia's previous knowledge and experiences with language teaching as language learner and student-teacher. Going back to the initial stages of Alicia at the very beginning of the course we encounter features such as lack of experience with network-based environments for learning and lack of identification with the potential of such environments for language learning. At the end of the first semester, we encounter Alicia consciously doing critical reflection regarding effective foreign language teaching; in the following extract, taken from one of her reports for the Teaching English as a Foreign Language methods class - $(\mathrm{TEFL})^{4}$, she grounds her teaching paradigm on her observations and experiences throughout the semester (December 2009). 
My paradigm of how to teach and learn a FL is based in some points. The first one is related to the environment. We live in a society in which we are constantly in touch with other languages (through music, TV, web pages, and so on) so we are unconsciously used to some communicative events in which a FL takes place... $\rightarrow$ A FL teacher should reinforce the natural input children receive by doing something useful and meaningful for students during English classes.

This leads me to the second point: embedded learning. Students should see -by their own- that learning a FL has a real purpose. If that happens, students will learn the FL motivated, knowing where are they and where do they want to arrive or what do they want to achieve.

Figure 4: Personal Reflection (wiki)

Further along the course, it is possible to see evidence that what began as an experiential activity of network-based environments and technologies -tools that were initially 'neutral' objects for pedagogical knowledge- turns into a specific conceptualization of the concept of collaboration, in which those objects acquire a specific significance and meaning for language teaching. In an activity designed for her TEFL Methods course (TEFL), Alicia identifies virtual collaboration as a valid practice to promote collaboration in her language classroom (figure 5).

Micro-teaching personal reflections
Before doing the micro-teaching I felt nervous although I knew the planning and steps to
follow. Moreover I was really worried about classroom management since I knew it would be
quite difficult to monitor group work, not only in that session but in any. Indeed, I have to
admit that every time students have to work in group I feel a little bit worried since I never
know if every single student has participated and learnt something new or not. But what I
learnt in this latter course, here at the university, is that a 100\% success dass is hardly
impossible to achieve as well as $100 \%$ control of the group. Moreover, in that moment I
thought our micro-teaching session was quite "risky" or "tricky" in the sense that it was not
topic-based but communicative language teaching (CLT) based, which was something much
broader. In short, let's remember how it was.
Our micro-teaching session was based on the CLT approach and was done using, firstly a
VoiceThread presentation and then group work- cooperative learning. To do this, we started
the session contextualizing the project and presenting the final product students were
expected to do further on: a VoiceThread presentation introducing themselves to Australian
students. In my eyes, the introduction and first part of the session were precise, condse and to
the point since students knew what they were expected to do. We wrote the session plan on
the board, so that students know explicitly what they would do in that particular session. We
gave students a real context and a real purpose in the use of English that went beyond the
classroom, so that was motivating for them. Additionally, we modeled an example of
VoiceThread presentation through which we hopefully answered indirect questions and
clarified some doubts.
As far as I am concerned, this first part went well but there were some things I would change if
I had to put it into practice again. Comments from Javier were good. He suggested to ask
students what they already know about Australia first (do like a kind of brainstorming); then
shnw snme images nf Australia (iust to five students ideas) and then desion the activitv sn that

Figure 5: Description of a Micro-Teaching Activity (Wiki) 
From this point of view, we could argue that she expands her conceptualization about doing collaborative teaching from the physical classroom to virtual environments through real (Internet-mediated) communicative events, although she herself does not use the term collaborative in her reports; instead she uses the term "cooperative work".

During the parallel TEFL methods course, Alicia encouraged her partner (who was not in the same teaching placement tutorial group as Alicia and therefore had not taken part in the telecollaborative exchange) to integrate telecollaboration in the design of the microteaching activity (mini-unit) that they had to present in their methods class. This mini-unit consisted of an introductory session, where the students had to introduce themselves to an Australian group of peers. Alicia announces the telecollaborative exchange to her classmates relating this practice to an English school project on countries aimed at students of 'cicle superior' (10-12 years old). She explains that this was not a topic-based activity but rather an experiential learning practice, which would allow students to learn English in an authentic environment:

\section{Extract 3: Introduction of micro-teaching activity, Alicia}

[...] we wanted to say before starting the activity that eh it embedded in uh an english school project on countries for cicle superior students so this is not this is not a topic-based activity but instead it's uh we've tried to to give students a real purpose for the use of English that goes beyond the class $u$ :h so we said them that they can see that the english is a powerful tool to communicate so they will have a real context and a real purpose [...] um i'm going to get in touch with an australian school so during throughout all the course they will get in touch via email via other multimedia resources.

She followed the same structure and adopted the same choice of media (VoiceThread) as the one in her own introductory meeting with her American peers:

Extract 4: Further explanation of micro-teaching activity, Alicia

[...] we started the session contextualizing the project and presenting the final product students were expected to do further on: a VoiceThread presentation introducing themselves to Australian students.

In her final report, where she explained the rationale guiding the decision to use telecollaboration as part of her microteaching session she stated that the telecollaborative project was an adequate way to achieve their objectives of organizing contextualized 
communicative events and language learning through group work that went beyond the traditional classroom:

Extract from Wiki (figure 5)

Our micro-teaching session was based on the CLT [Communicative Language Teaching] approach and was done using, firstly a VoiceThread presentation and then group work - cooperative learning [...]. We built it up from the basis that we wanted to create a micro-teaching plan which has some purposeful and contextualized communicative events. I believe that was the reason why we finally imagined we would get in touch with an Australian school.

Moreover, she related that this network-based activity would foster students' motivation by engaging them in purposeful language learning: "We gave students a real context and a real purpose in the use of English (our emphasis) that went beyond the classroom, so that was motivating for them".

What is also interesting to note is that Alicia, in her rankings of the EPOSTL criteria for student teachers of language, classifies the competence to integrate telecollaborative activities into teaching practices to promote project-based learning as number one. In her end of the year reflection, she highlights it as a competence that she felt she had come to acquire to the extent of understanding its value and engaging in the organization.

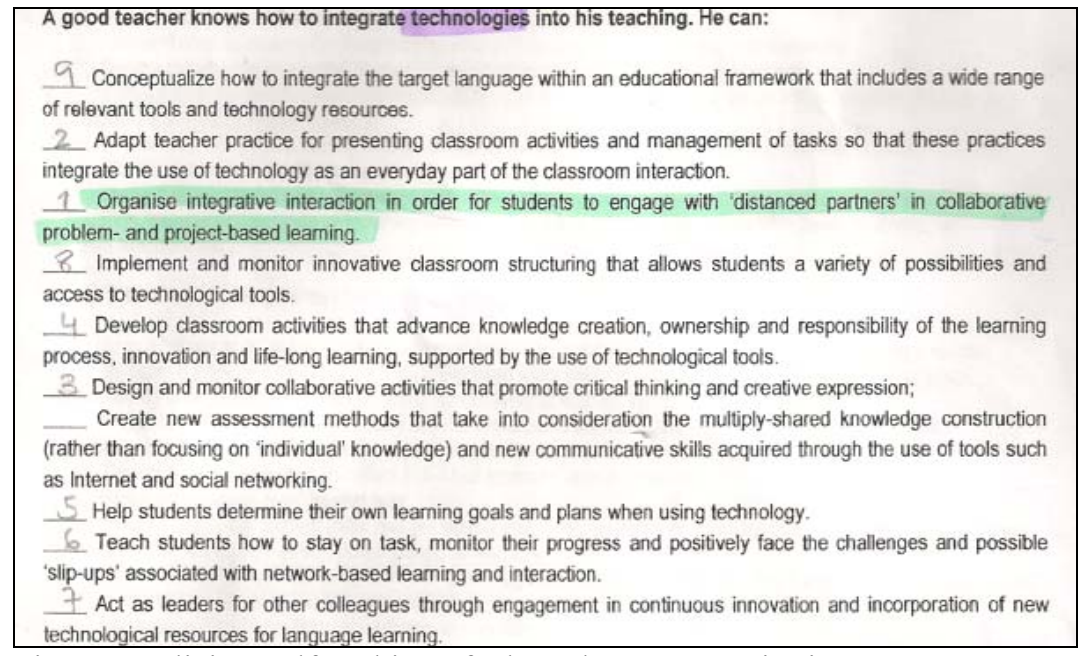

Figure 6: Alicia's self-ranking of adapted EPOSTL criteria

Overall, the learning outcome consists in applying what the subject has been exposed to and what she has internalized/appropriated during her own experience with telecollaboration i.e., types of technologies, in this case Voicethread, as a good tool for 
telecollaboration, as well as concepts of authentic language learning through intercultural communication.

\section{Limitations}

This investigation forms part of a doctoral thesis, for which the data collection process abided to a pre-determined period of time (1 year). Thus, the data do not permit examination of this development further in time and the application of the new knowledge (about telecollaboration) in new contexts i.e., in actual professional practices in order to argue for sustainability of results. What, at this stage, may appear as a shortcoming poses the challenge - and need, for a follow-up study on this group of students in order to examine the possibility of sustainable results. In the interim, this study acknowledges the possibility of regression to old practices of teaching that may not include telecollaboration or even collaboration. But at the same time, we need to acknowledge that regression may also depend on the social and material conditions of the schools including factors such as school culture, technological infrastructure, time-frames and so on.

\section{Summary and conclusions}

This article reports the findings of a study of a teacher training course that was designed according to sociocultural views of learning. The virtual setting acted as both the mediator and the medium, in which the language-mediated collaborative events took place. The sociocultural nature of the learning environment is indicated in the creation of an authentic learning environment structured around a problem-solving activity (design a teaching sequence), where the participants use their knowledge to construct and reconstruct/transform the meaning of tools (semiotic e.g., language and physical e.g. technologies, network-based environments); thus mediate cognitive development e.g., teacher-related knowledge and skills.

One important implication of setting up collaborative settings, emphasized by proponents of collaborative learning, and supported in the findings of this study, is that the active exchange of ideas within small groups promotes critical thinking (Gokhale, 1995; Johnson \& Johnson, 1986). The discussion about the affordances of collaborative settings for promoting critical thinking has been, to a large extent, led by researchers in non CMC 
settings. This study argues for the integration of telecollaborative settings in teacher education as another concrete example of collaborative practice which would allow teachers to learn about and critically think about scientific meaning of collaborative authentic language teaching and learning by means of concrete practice, as in the case of this student-teacher investigated here.

Effectively integrating telecollaboration in pre-service teacher education programmes has the potential to provide situated opportunities for learning about collaboration, technologies, network-based teaching and learning of language in real authentic contexts and to come closer to bridging what has been called the gap between social and educational uses of technology (Dooly, 2009) relevant to the characteristics of Teacher 2.0.

\section{References}

Antoniadou, V. (2011). Using Activity Theory to understand the contradictions in an online transatlantic collaboration between student-teachers of English as a Foreign Language. ReCALL 23(3): 233-251.

Barab, S.A., Hay, K.E., \& Yamagata-Lynch, L.C. (2001). Constructing networks of actionrelevant episodes: An in situ research methodology, The Journal of the Learning Sciences, 10 (1\&2), 63-112.

Daniels, H. (2008). Vygotsky and Research. Routledge.

Dooly, M. (2009). New competencies in a new era? Examining the impact of a teacher training project. ReCALL, 21 (3): 352-369.

Dooly, M. (2010). Teacher 2.0. In S. Guth \& F. Helm (eds) Telecollaboration 2.0: Language, Literacies and Intercultural Learning in the 21st Century, pp. 277-303. Bern: Peter Lang.

Dooly, (2011). Divergent perceptions of telecollaborative language learning tasks: Tasksas-workplan vs. task-as-process. Language Learning \& Technology, 15(2): 69-91.

Egbert, J., M. Paulus, T. M., \& Yoko Nakmichi, Y. (2002).The impact of CALL instruction on classroom computer use: A Foundation for Rethinking Technology in Teacher Education. Language Learning \& Technology 6(3): 108-126. Available at: vol6num3/egbert/default.html

Glaser, B. G., \& Strauss, A. L. (1967). The discovery of grounded theory. Hawthorne, NY: Aldine.

Gokhale, A.A. (1995). Collaborative learning enhances critical thinking. Journal of Technology Education 7(1). Available at: $\underline{\text { http://scholar.lib.vt.edu/ejournals/JTE/v7n1/gokhale.jte-v7n1.html }}$ 
Golombek, P.R., \& Johnson, K.E. (2004). Narrative inquiry as a mediational space: Examining emotional and cognitive dissonance in second-language teachers' development. Teachers and Teaching: Theory and Practice, 10(3), 307-327.

Johnson, K. E., \& Golombek, P. R. (2003). Seeing teacher learning. TESOL Quarterly, 37, 729-738.

Johnson, R. T., \& Johnson, D. W. (1986). Action research: Cooperative learning in the science classroom. Science and Children, 24: 31-32.

Johnson, K. E. (2006). The sociocultural turn and its challenges for L2 teacher education. TESOL Quarterly, 40, 235-257.

Johnson, K. E. (2009). Second language teacher education: A sociocultural perspective. New York: Routledge

Lantolf, J. P., \& Thorne, S. L., (2006). Sociocultural theory and the genesis of L2 development. Oxford: Oxford University Press.

Newby, D., Allan, R, Fenner, A.B., Jones, B., Komorowska. H., \& Soghikyan, K. (2007). European portfolio for student-teachers of language: A reflection tool for language teacher education. Graz: ECML.

Rogoff, B. (2003). The cultural nature of human development. New York: Oxford University Press.

Veresov, N. (2008). CHAT in retrospective: Bridging the gap or fixing the hole? Paper presented at the International Society for Culture and Activity Research, San Diego, USA

Vygotsky, L. S. (1978). Mind in Society: The development of higher psychological processes. Cole, M. John-Steiner, V., Souberman, E. (eds.). Cambridge, Mass.: Harvard University Press.

Vygotsky, L.S (1981). The genesis of Higher Mental Functions. The concept of activity in Soviet psychology. Wertsch, J. (ed.), New York. M.E. Sharpe, pp.144-188.

Vygotsky, L.S (1986). Thought and language. Cambridge, MA: MIT Press.

Wertsch, J. V. (1991) Voices of the mind: A sociocultural approach to mediated action. Cambridge, MA: Harvard University Press.

Zinchenko, V. P. (1985). Vygotsky's ideas about units for the analysis of mind. In Culture, Communication and Cognition: Vygotskian Perspectives. Wertsch, J.V. (ed.) New York: Cambridge Univ. Press, 1985: 94-17.

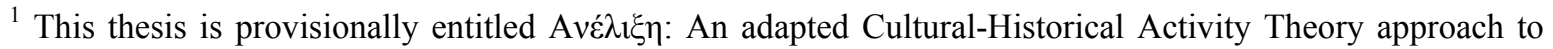
teacher education and telecollaboration and is being developed under the close supervision of Dr. Melinda Dooly.

${ }^{2}$ The recordings were transcribed using the ELAN software. The phonological aspects of the interactions e.g. intonation, stress have not been taken into account in the transcription since the research was more concerned with what it was said rather than the way it was said.

${ }^{3}$ The names of the participants have been changed to ensure anonymity.

${ }^{4}$ The researcher was able to obtain these data because the teacher of the Teaching Methods course was the same person as the Practicum Tutorial Advisor. 